\title{
An Analysis of Linear Algebra Teaching Problems and Solutions
}

\author{
Jianming Liu \\ College of Mathematics and Computer Science, Quanzhou Normal University, \\ Quanzhou 362000, Fujian, P. R. China \\ Fujian Provincial Key Laboratory of Data Intensive Computing, Quanzhou Normal University, \\ Quanzhou 362000, Fujian, P. R. China \\ liujmcqu1999@sina.com
}

Keywords: Mathematics teaching situations, Practical solutions, Linear algebra teaching quality

\begin{abstract}
The paper aims at examining real mathematics teaching situations existing in local universities and colleges and exploring relative practical solutions to these problems. Based on a thorough study on mathematics teaching situations and related experts' research reports, the author's in-depth discussion with seasoned mathematics teachers and his own teaching experiences, the paper displays his advice on improving linear algebra teaching quality in higher educational system from three aspects: classroom teaching, exercise selection and explanation and after-class studying communication and guidance.
\end{abstract}

\section{Introduction}

As is known to us, mathematics courses play a special role in higher educational course systems, whose teaching quality can not only exert an influence on colleges students' comprehensive quality improvement, but also affect their further study and development. Take linear algebra as an example. It is a basic and important mathematics course for college students of polytechnic and economics students [1,2]. However, to local universities and colleges, they are confronted with a very serious situation: firstly, compared with students of key universities, most students of local universities got a low score in math in China's college entrance examination, which means these students' math is very poor. Secondly, these students need teachers' guidance when studying abstract linear algebra. However, instead of paying attention to these students' needs for teachers' guidance in mathematics, local universities reduce math credits and teaching periods, which lead to the fact that many students have great difficulties into studying mathematics and improving their studying quality. Therefore, how to improve linear algebra teaching quality in local universities and colleges becomes an urgent problem. As a university teacher in charge of linear algebra teaching for many years, the author did a thorough study on this serious teaching situation and discussed with many seasoned mathematics teachers in order to seek a solution. And his advice on solving this problem are demonstrated as follows from three aspects: classroom teaching, exercise selection and explanation and after-class studying communication and guidance.

\section{The First Aspect: Classroom Teaching}

As for classroom teaching, I believe that to give a good beginning is of great importance. What does it mean to give a good beginning? And why does it matter so much?

To give a good beginning is that teachers should do thorough research on students' real situation in studying mathematics before learning linear algebra and make enough preparations. Most majors in local universities and colleges start linear algebra course in the second term of the freshman year or the first term of the sophomore year. Therefore, in the first class of linear algebra lectures, teachers should make efforts to make students understand that compared with advanced mathematics course they have already learned, liner algebra course is different from it in reasoning, for linear algebra is characteristic of strong logic thinking and abstract calculating. And then, to further point out these differences, teachers should make a brief introduction to the course to make students get to know its 
components, significant importance, learning purposes, learning methods and teaching plans in the succeeding term. Besides, teachers might as well pay attention to students' majors, for different majors ask for different requirements for mathematics calculation abilities. After being informed of students' majors, teachers will then think over the application of linear algebra in these majors in real life and their connections. To help students aware of the importance of these connections, teachers can prepare related real examples and demonstrate in the first class of linear algebra. In a word, all of these preparations serve as useful methods to give students a good beginning when studying linear algebra, which will thoroughly dispel students' doubt as what studying the course for and inspire their interest in studying the course.

In classroom teaching, teachers should cultivate friendly atmosphere of teaching and learning. Teachers play a major role in class teaching, which means high teaching quality depends on teacher's teaching ability and students' active cooperation. To achieve this, teachers should create harmonious class atmosphere. Relaxing and interesting study atmosphere is conducive to bringing students' inner learning incentive and potential into full play. Moreover, teachers should show their love and hope for students, display their enthusiasm as well as combine their emotions with the teaching process. Thus, students can focus on the class and study happily. And students' mind activities will be more active by teachers' inspiration, which help improve their study ability.

Teachers should introduce aesthetic education in the course of the class teaching. Aesthetic education can help people feel beauty and cultivate their esthetic sentiment before they know it as well as enjoy spiritual contentment and happiness. Introducing aesthetic education into linear algebra class teaching can promote students to master knowledge construction, open their minds, improve their interests in math study and cultivate their love for science. Therefore, teachers should explore the potential aesthetic elements of teaching content and improve their own aesthetic ability. Meanwhile, they should design beautiful teaching situation, delicately display aesthetic elements contained in algebra and make splendid PPT with beautiful mathematical language, elegant teaching posture and other methods to carry out aesthetic education.

In the course of math class teaching, it's necessary to introduce the background and history of mathematics concepts, which can help students understand mathematical culture more comprehensively and improve their mathematical attainment. If teachers can introduce relative background of some concepts and history of linear algebra development, for example, lifetime and accomplishment of mathematicians home and abroad, to make students understand the background and development of linear algebra, the teaching class will be more interesting while the teaching atmosphere will be more relaxing, which will be beneficial to students' full understanding and master of the knowledge.

Moreover, teachers should bring computer teaching method into full play. Computer auxiliary education can not only rich teaching methods, but also make dull teaching contents more interesting and easier to understand. Meanwhile, it can avoid repeated work by reducing blackboard writing and thus improving teaching efficiency. However, much teaching practices show that using multimedia education methods throughout the whole mathematics teaching class will result in poorer teaching efficiency. According to most students' responses, they find that just watching PPT on the computer screen in the whole teaching class makes them feel tired, hard to make notes in time, hard to think and understand mathematical concepts. As a result, after the class, they find they learn nothing. Therefore, if teachers only rely on multimedia education method, students will suppose that they are watching pictures in class. Therefore, to exert the advantages of computer auxiliary education method fully, optimize class teaching, improve class teaching efficiency and inspire students' learning enthusiasm, teachers should use multimedia reasonably in accordance with teaching content.

Meanwhile, we should notice that due to university enrollment increase, more students enter universities and colleges and students' study background varies, which will increase teachers' difficulties in giving mathematics lectures. Therefore, we can take class teaching into consideration. For example, we can classify linear algebra course into Degree A、B and C according to different 
majors and give courses according to major requirements. Or we can set linear algebra into compulsory course and students can freely choose teachers and class.

\section{The Second Aspect: Exercise Selection and Explanation}

Exercise choosing and explaining is a critical part of mathematics teaching. To select good exercise, teachers should follow these pieces of advice: first, choosing typical exercise that is concerned about relative mathematics knowledge and can help train students' understanding; second, choosing targeted exercise. Different from class teaching, exercise class focuses on training. To achieve efficient training goals, teachers should base exercise selecting on learning objectives, examining knowledge and students' real learning situations, especially those mistakes students make repeatedly. To put it more accurately, teachers can further clear, conclude, summarize last chapter's content and help students understand relative linear algebra knowledge points during exercise class. Teachers can also explain exercise, point out and correct problems in students' assignments on exercise class. Besides, they can choose some typical exercise examples to explain, especially some mathematics exercise with different solutions, thus to urge students to think and perform mathematics calculations. This can develop students' ability of analyzing and solving questions and divergent thinking as well as inspiring their learning enthusiasm and activating learning atmosphere.

Moreover, it is noticeable that practical mathematics teaching is a new trend of mathematics course teaching in the information era. Nowadays, with great development of computers, the wide application of such mathematics software as MATHEMATICA、MATLAB、MATHCAD and MAPLE requires that linear algebra teachers should keep up with the times and adjust teaching process of linear algebra. To overcome disadvantages of traditional teaching methods and achieve our country's requirement on higher education reform, local universities and colleges should consider opening experiment courses with computer operation as its main teaching activity and mathematics software as its main teaching content. In fact, many universities have already opened mathematics experiment courses and acquired good responses.

\section{The Third Aspect: After-class Studying Communication and Guidance}

Giving top priorities to after-class communication between teachers and students is beneficial to teaching quality improvement. In universities, it is common that there is little communication between teachers and students after class. Lots of teachers go to classroom and leave it the moment the bell rings. Therefore, to make up for the deficiency of regular class teaching, teachers should pay attention to their after-class communication with students. For example, teachers can tell students their office address and telephone, so that students can turn to them for help conveniently on mathematics problems. And teachers should actively listen to students, make friends with them and talk about their learning situation and so on, which can not only make closer relationship between them but also help improve teaching efficiency and quality.

Besides, some students find that linear algebra course is so difficult that they cannot understand lectures given by teachers in class. Meanwhile, most linear algebra teachers are young and lack class teaching experience. Therefore, teachers should carry out guidance to some students after class by means of establishing QQ groups and webs of mathematics learning communication or e-mails to help solve problems that students encounter while studying linear algebra. Only by giving timely and efficient guidance can teachers help solve students' mathematics problems, get to know relationship between teaching schedule and students' understanding situation, thus adjust teaching content and schedule in time, make sure all students can smoothly finish their linear algebra learning, comprehensively improve linear algebra teaching quality and make up for the deficiency in poor communication between teachers and students in big class teaching.

While talking to students, teachers should encourage them to ask questions, join in teaching activities and cultivate their ability of thinking and resolving questions. Improvement in these abilities can be a good guarantee for teaching quality. 
In a word, to improve linear algebra teaching quality in local universities and colleges is a matter worth contemplating and carrying out. Teaching is not only giving lectures, but also a kind of art, which requires that teachers should continuously conclude and summarize in practice and improve their own ability. Meanwhile, they need to establish harmonious and friendly relationship with students and promote their cooperation and communication. Thus, both teachers and students can reap the harvest of personal ability development and improvement. Just as the old famous saying puts it, teaching benefits teachers as well as students.

\section{Conclusion}

The paper is concerned about the author's exploration into linear algebra teaching improvement in local universities and colleges. Local universities and colleges are faced with students with poor mathematics and reduced mathematics credits, all of which do great harm to students' studying linear algebra well. To tackle this serious situation, teachers should pay great attention to their improvement in teaching process, exercise selection and explanation and after-class studying communication and guidance.

\section{Acknowledgements}

This work was supported by Fujian Provincial Key Laboratory of Data Intensive Computing and Key Laboratory of Intelligent Computing and Information Processing, Fujian Province University.

\section{References}

[1]Dept. of Applied Mathematics, Tongji University, Engineering Mathematics_— Linear Algebra, fifth ed., edtied by Higher Education Press, Beijing(2010).

[2]Dept. of Mathematics, Peking University, Advanced Algebra, fourh ed., edtied by Higher Education Press, Beijing(2013). 